\title{
Existence of Neural Crest-Derived Progenitor Cells in Normal and Fuchs Endothelial Dystrophy Corneal Endothelium
}

\author{
Kishore Reddy Katikireddy, ${ }^{*}$ Thore Schmedt, ${ }^{* \dagger}$ Marianne 0. Price, ${ }^{\ddagger}$ Francis W. Price, ${ }^{\S}$ and Ula V. Jurkunas ${ }^{*}$
}

From the Schepens Eye Research Institute, ${ }^{*}$ Massachusetts Eye and Ear, Boston, Massachusetts; AbbVie Deutschland GmbH \& Co KG, ${ }^{\dagger}$ Ludwigshafen, Germany; the Cornea Research Foundation of America, ${ }^{\ddagger}$ Indianapolis, Indiana; and the Price Vision Group, ${ }^{\S}$ Indianapolis, Indiana

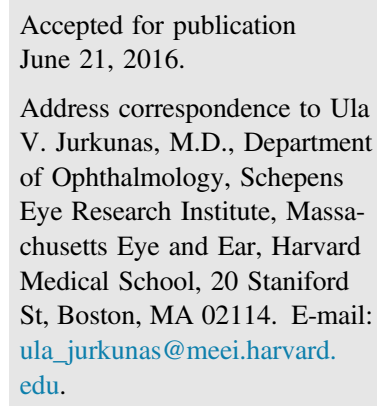

\begin{abstract}
Human corneal endothelial cells are derived from neural crest and because of postmitotic arrest lack competence to repair cell loss from trauma, aging, and degenerative disorders such as Fuchs endothelial corneal dystrophy (FECD). Herein, we identified a rapidly proliferating subpopulation of cells from the corneal endothelium of adult normal and FECD donors that exhibited features of neural crest-derived progenitor (NCDP) cells by showing absence of senescence with passaging, propensity to form spheres, and increased colony forming efficacy compared with the primary cells. The collective expression of stem cell-related genes SOX2, OCT4, LGR5, TP63 (p63), as well as neural crest marker genes PSIP1 $\left(\mathrm{p} 75^{\mathrm{NTR}}\right), P A X 3$, SOX9, AP2B1 (AP-2 $\left.\beta\right)$, and NES, generated a phenotypic footprint of endothelial NCDPs. NCDPs displayed multipotency by differentiating into microtubule-associated protein $2, \beta$-III tubulin, and glial fibrillary acidic protein positive neurons and into $p 75^{N T R}$-positive human corneal endothelial cells that exhibited transendothelial resistance of functional endothelium. In conclusion, we found that mitotically incompetent ocular tissue cells contain adult NCDPs that exhibit a profile of transcription factors regulating multipotency and neural crest progenitor characteristics. Identification of normal NCDPs in FECD-affected endothelium holds promise for potential autologous cell therapies. (Am J Pathol 2016, 186: 2736-2750; http://dx.doi.org/10.1016/j.ajpath.2016.06.011)
\end{abstract}

Human corneal endothelial cells (HCEnCs) form a monolayer of hexagonal cells on the posterior surface of the cornea and are essential for maintaining appropriate corneal hydration necessary for clear vision. HCEnCs sustain corneal clarity by serving as a barrier between the aqueous humor and the corneal stroma and by active ionic transport that regulates the swelling pressure of the cornea. HCEnCs are arrested in the postmitotic state and have limited proliferative capacity both in vivo and in vitro. The postmitotic arrest has been attributed to contact inhibition, transforming growth factor- $\beta$ in aqueous fluid, and lack of paracrine stimulation by growth factors of cell-cycle promotion from the $G_{1}$ to the $S$ phase. ${ }^{1}$ In a normal human life span, the endothelial cell density gradually declines. ${ }^{2}$ Therefore, age- and disease-related HCEnC loss is a major cause of corneal blindness requiring corneal transplantation to restore vision. Specifically, Fuchs endothelial corneal dystrophy (FECD) is the most common cause of endogenous endothelial cell dysfunction; it is associated with progressive cell apoptosis and concurrent extracellular matrix deposition in the form of guttae and is primarily treated by allogeneic endothelial keratoplasty., ${ }^{3,4}$ The pathogenic mechanism behind FECD is purportedly related to the interplay between genetic mutations and environmental factors.

Several reports have proposed the existence of endothelial progenitor cells situated in the peripheral cornea, but evidence so far has not been conclusive. ${ }^{6-8}$ The description of purported stem cells (SCs) has been based on ex vivo

Supported by Falk Medical Research Foundation, Cornea Donor Research Fund, NEI/NIH grant RO1EY020581 (U.V.J.), and NIH/NEI Core grant P30EYE003790.

Disclosures: T.S. is employed by AbbVie Germany GmbH \& Co KG and owns stock in AbbVie Inc. M.O.P. and F.W.P. consult for Transcend, Staar Surgical, and Haag-Streit and have investments in Calhoun Vision, RevitalVision, TearLab, Strathspey Crown, and Interactive Medical Publishing. 
staining of tissue with progenitor markers ${ }^{7,9,10}$ or isolation of progenitor-like cells in vitro based on sphere-forming culture $^{8,11,12}$ or surface markers. ${ }^{6,13}$ However, there is no direct evidence of the existence of multipotent HCEnC cells in the corneal endothelial layer.

The refutability of the existence of HCEnC progenitors in the adult population is supported by the lack of self-renewing competence and permanent cell loss from trauma, aging, and disease, such as FECD. Moreover, HCEnCs have very low proliferative potential in vitro manifesting in limited passaging ability, rapid cellular senescence, and eventual endothelial mesenchymal transition. ${ }^{1,14,15}$ The corneal endothelium in FECD has an even lower replicative capacity than that from normal corneas, and, for the most part, transduction with viral oncogenes is required to stimulate cell growth in vitro. ${ }^{16,17}$ Because of the age-related nature of FECD, the median age at the time of endothelial keratoplasty is 70 years. Cultures of primary FECD cells from the central cornea of these older donors often cannot be initiated because of the low number of viable cells. ${ }^{18}$ Most studies, including our own unpublished data, show that FECD CEnCs can be passaged for only one to two passages, unless transduced with Simian virus 40 or E6/E7 oncogenes, because of low proliferative potential and rapid senescence. ${ }^{19}$ To date, there is a scarcity of evidence regarding how to generate uniform and functional corneal endothelium from SCs, and corneal tissue remains the only source of normal or FECD HCEnCs.

The corneal endothelium is derived from cranial neural crest cells, ${ }^{20}$ which migrate from the margins of the optic cup behind the surface ectoderm (future anterior corneal surface) and form an initial double layer of cells that becomes a single layer of flattened cells with apical-basal polarization and apical tight junctions. HCEnCs rest on the posterior corneal surface on their basement membrane, called Descemet's membrane, and become mitotically incompetent in the postnatal life. Similar to corneal endothelium, on initial migration, neural crest gives rise to several other mitotically incompetent cell types such as neurons, glial cells, myofibroblasts, and adipocytes that contribute to the formation of distinct tissues and organs. ${ }^{21}$ Interspersed among populations of differentiated cells, neural crest SCs (NCSCs) retain their multipotency and have the ability to differentiate into a number of neural crest derivatives. To date, NCSCs have been isolated from skin, ${ }^{22-24}$ a variety of neuronal tissues, ${ }^{25,26}$ and heart ${ }^{27}$ but not corneal endothelium. Interestingly, NCSCs have been recovered from the corneal stroma, which is populated with a mixture of keratocytes and mesenchymal cells and has a distinct phenotype and function in the cornea. ${ }^{28}$ Because stromal keratocytes share the embryologic lineage with corneal endothelium, we hypothesized that the corneal endothelial monolayer harbors neural crest-derived endothelial progenitor cells that are capable of perpetual division by retaining the potential to differentiate into other neural crest derivatives. We used our previously developed sphere formation assay ${ }^{29}$ to characterize the distinct populations of endothelial cells isolated from normal and FECD corneas and to further investigate whether these cells retain their multipotency by differentiating into other neural crest derivatives after induction with neuronal differentiation medium. Interestingly, we detected that not only normal but also FECD endothelial tissue harbor progenitor cells that seem to be unaffected by the diseased state. In this study, we identified the unique characteristics of progenitors that are of neural crest lineage in mitotically incompetent cells of the ocular tissue.

\section{Materials and Methods}

\section{Corneal Endothelial Tissue Specimens}

The study was approved by the Institutional Review Board of Schepens Eye Research Institute, Massachusetts Eye and Ear, Boston, MA. Written informed consent was acquired from FECD patients before Descemet membrane (DM) endothelial keratoplasty at Price Vision Group (Indianapolis, IN). The surgical specimens were maintained and transported in Optisol (Bausch \& Lomb Incorporated, Rochester, NY). Normal human donor corneas were obtained from National Disease Research Interchange (Philadelphia, PA).

\section{Establishment of Primary HCEnCs}

Donor corneas were obtained according to exclusion criteria reported previously ${ }^{30}$ and were maintained in corneal storage medium (Optisol) at $4^{\circ} \mathrm{C}$ until immediately before isolation of CEnCs. Primary cells were cultured according to previously published methods ${ }^{31}$ with minor modifications. Briefly, after dissection of DM with intact endothelium and overnight stabilization in Chen's medium (OptiMEM-I; Invitrogen, Carlsbad, CA), $8 \%$ fetal bovine serum (HyClone, Rockford, IL), $5 \mathrm{ng} / \mathrm{mL}$ epidermal growth factor (Millipore, Billerica, MA), $100 \mu \mathrm{g} / \mathrm{mL}$ bovine pituitary extract (Invitrogen), $200 \mathrm{mg} / \mathrm{L}$ calcium chloride (Sigma-Aldrich, St. Louis, MO), $0.08 \%$ chondroitin sulfate (Sigma-Aldrich), 50 $\mu \mathrm{g} / \mathrm{mL}$ gentamicin (Invitrogen), and 1:100 diluted antibiotic/ antimycotic solution (Sigma-Aldrich). The strips were incubated in $0.02 \%$ EDTA solution (Sigma-Aldrich) at $37^{\circ} \mathrm{C}$ for 1 hour and mechanically disrupted by trituration. ${ }^{30}$ Cell suspensions were plated in 12-well tissue culture plates precoated with undiluted FNC Coating Mix, a specially formulated reagent that dramatically increases the attachment of cells to the plastic substratum used for culturing mammalian cells (AthenaES, Baltimore, MD). Subculturing of CEnCs was performed using 0.05\% trypsin (Invitrogen) for 5 minutes at $37^{\circ} \mathrm{C}$. Phase-contrast micrographs were obtained using a Leica Microscope (LAS V 4.5; Leica Microsystems Inc., Wetzlar, Germany).

\section{CFE of HCEnCs}

Colony forming efficacy (CFE) was determined as previously reported. ${ }^{29}$ In brief, 300 to 500 cells per well were 
plated onto FNC-coated 6-well plates in SC medium consisting of knockout embryonic SC/induced pluripotent SC medium, supplemented with $1 \%$ nonessential amino acids, $1 \%$ penicillin-streptomycin, $1 \%$ L-glutamine (all from Invitrogen), $10 \mathrm{ng} / \mathrm{mL}$ leukemia inhibitory factor (PeproTech, Rocky Hill, NJ), and $4 \mathrm{ng} / \mathrm{mL}$ human epidermal growth factor. The cells were cultured for 14 days. The colonies were washed once with phosphate-buffered saline to eliminate growth media on day 14 and stained with 5\% crystal violet (Sigma-Aldrich) for 5 minutes. CFE was calculated as $\mathrm{CFE} \%=$ (colonies formed at end of growth period $\times$ $100 \%) /$ total number of viable cells seeded. CFEs were calculated from six independent experiments.

\section{CDT}

Cells were plated in FNC-coated 12-well plates at a density of 50,000 cells per well, and the medium was replenished every 2 days. Cells were treated with $0.05 \%$ trypsin, and the cell number was quantified using Countess (Invitrogen) at 2, 3, and 4 days after seeding. Cell numbers were determined for duplicate wells per time point. The average cell doubling time (CDT) was calculated from six independent experiments.

\section{SF}

From slowly proliferative primary cells, subpopulations of neural crest-derived progenitors (NCDPs) growing in uniform colonies were separated manually and subcultured further. The isolated NCDPs were trypsinized, and cell number was determined by a trypan blue exclusion test with Countess Cell Counter. Approximately 2500 viable cells/ $\mathrm{cm}^{2}$ were seeded onto uncoated bacteriological plates in sphere formation (SF) medium, containing 1:1 Dulbecco's modified Eagle's medium/F12, 2\% B27, 1\% N-2 Supplement (all from Invitrogen), $20 \mathrm{ng} / \mathrm{mL}$ basic fibroblast growth factor (PeproTech), $2.5 \mathrm{mmol} / \mathrm{L} \mathrm{L}$-glutamine, $50 \mu \mathrm{g} /$ $\mathrm{mL}$ gentamicin, and 1:100 diluted antibiotic/antimycotic solution. The cells were cultured for 7 days to promote the formation of spheres with the medium changed every 2 days. The total number of spheres represents spheres that were at least $50 \mu \mathrm{m}$ in diameter. The spheres were collected, replated on 1\% Matrigel-coated plates (BD Biosciences, San Diego, CA) for 7 days to enhance progenitor colonies, and used for RNA isolation and immunofluorescence staining.

\section{Immunocytochemical Analysis of Spheres}

Individual primary spheres grown on bacteriologic plates at day 7 were transferred to 4-well chamber slides (Invitrogen) coated with $1 \%$ Matrigel. Attached spheres were allowed to grow for 3 to 4 days in SC medium and then analyzed for $\mathrm{SC}$ markers. Immunohistochemistry was performed as previously described. ${ }^{29}$ Briefly, cells were fixed with cold methanol and acetone (1:1 ratio), permeabilized with $0.2 \%$ Triton X-100 (Sigma-Aldrich), blocked with $5 \%$ bovine serum albumin for 1 hour, and incubated with primary and secondary antibodies as described in Table 1. An isotype control was used as a negative control; the primary antibody was omitted, and a nonspecific mouse monoclonal IgG (Millipore) was used instead. The nuclei were stained with $100 \mu \mathrm{g} / \mathrm{L}$ propidium iodide (Sigma-Aldrich) for 2 minutes. After washing three times in phosphate-buffered saline, slides were mounted with DAPI (Vectashield; Vector Laboratories, Burlingame, CA). Images were obtained with a laser scanning confocal microscope (TCS SP5 CLSM; Leica, Buffalo Grove, IL). For each sample, high-resolution images in Z-stacks were collected and a final image was obtained by reconstruction of all stacks with Leica LAS AF Lite software version 2.1.0.

\section{RNA Extraction, and Real-Time PCR and RT-PCR}

Cells grown on $1 \%$ Matrigel were lyzed with Trizol (Invitrogen), and aqueous phase was prepared according to the manufacturer's protocol. The aqueous phase was mixed with $70 \%$ ethanol, and RNA extraction was performed with RNeasy Micro Kit with in-column DNase I digestion according to the manufacturer's protocol (Qiagen, Valencia, CA). RNA quality and quantity were measured using a

Table 1 Antibodies Used for Immunofluorescence Staining

\begin{tabular}{lll}
\hline Antibodies & Source/catalog number & Dilution \\
\hline Oct4 (octamer-binding protein 4) & Abcam (Cambridge, MA)/ab18976 & $1: 100$ \\
TRA-1-60 & Abcam/ab16288 & $1: 100$ \\
SSEA4 (stage specific embryonic antigen) & Abcam/ab16287 & $1: 100$ \\
Mouse monoclonal IgG & Millipore (Billerica, MA)/12-371 & $1: 50$ \\
LGR5 & Santa Cruz Biotechnology (Dallas, TX)/sc-68580 & $1: 500$ \\
Anti-p75NTR (neurotrophin receptor) & Millipore/07-476 & $1: 500$ \\
$\mathrm{Na}^{+} / \mathrm{K}^{+}$-ATPase & Santa Cruz Biotechnology/sc-28800 \\
Z0-1 & Sigma-Aldrich (St. Louis, M0)/SAB1306492 \\
Anti-GFAP (glial fibrillary acidic protein) & Abcam/ab7260 \\
Anti-microtubule-associated protein 2 (MAP2) & Millipore/AB5622 & $1: 600$ \\
$\beta$-III tubulin & Santa Cruz Biotechnology/sc-51670 \\
Alexa Fluor 488 anti-mouse IgG & Invitrogen (Carlsbad, CA)/A-11001 \\
Alexa Fluor 647 anti-rabbit IgG & Invitrogen/A-11008 & $1: 1000$ \\
\hline
\end{tabular}


Table 2 Assay ID and Probe Sequences Used for Real-Time PCR Assay ID (TaqMan

\begin{tabular}{ll} 
Gene name & $\begin{array}{l}\text { Assay ID (TaqMan } \\
\text { expression assay) }\end{array}$ \\
\hline GAPDH & Hs99999905_m1 \\
TP63 (p63) & Hs00978340_m1 \\
OCT4 (0ctamer-binding protein 4) & Hs00999634_gH \\
Sox2 (P0U family binder & Hs00415716_m1 \\
$\quad$ transcription factors) & \\
LGR5 & Hs00969422_m1 \\
SOX9 & Hs01001343_g1 \\
PAX3 & Hs00240950_m1 \\
NES & Hs04187831_g1 \\
AP2B1 & Hs00426694_m1 \\
PSIP1 (p75 & Hs00609976_m1 \\
\hline
\end{tabular}

ID, identification.

NanoDrop (LabTech International, Uckfield, UK). Two micrograms of total RNA was reverse-transcribed in a $20-\mu \mathrm{L}$ reaction volume iScript cDNA synthesis kit (BioRad, Hercules, CA), according to the manufacturer's protocol. The TaqMan primers listed in Table 2 were obtained from Applied Biosystems (Foster City, CA). Real-time PCR was performed in a Mastercycler Realplex2 (Eppendorf, Hamburg, Germany) as triplicates with Probe Fast Master Mix (Kapa Biosystems, Wilmington, MA). The relative expression of each gene was evaluated in at least three different passages for each cell type. No-template reactions were performed for each assay as negative controls. The results were normalized to their respective $G A P D H \mathrm{C}_{\mathrm{T}}$ values. The relative expression was calculated by subtracting normalized $\mathrm{C}_{\mathrm{T}}$ values of the reference sample (nondividing primary cells) from the experimental value and expressed as $2^{-\Delta \Delta C T}$.

\section{Differentiation of NCDPs}

NCDPs grown as spheres on uncoated bacteriologic plates were trypsinized, and single-cell suspensions were seeded at $2.5 \times 10^{4}$ cells $/ \mathrm{cm}^{2}$ on glass coverslips coated with $100 \mu \mathrm{g} /$ $\mathrm{mL}$ poly-d lysine and $20 \mu \mathrm{g} / \mathrm{mL}$ laminin (both from SigmaAldrich). The cultures were induced with STEMdiff Neural Induction Medium (Stemcell Technologies Inc., Vancouver, Canada) for 7 days and tested for the expression of glial fibrillary acidic protein, microtubule-associated protein 2 , and $\beta$-III tubulin. To induce differentiation of NCDPs to $\mathrm{CEnCs}$, single-cell suspensions from spheres were seeded onto FNC-coated coverslips in Chen's medium for 7 days before immunofluorescence staining with $\mathrm{ZO}-1, \mathrm{Na}^{+} / \mathrm{K}^{+}$ ATPase, and $\mathrm{p} 75^{\mathrm{NTR}}$.

\section{TEnR}

Transendothelial resistance (TEnR) was measured as described previously. ${ }^{31}$ In brief, spheres generated from NCDPs at earlier and late-passages were trypsinized and plated on FNC-coated, 12-well transwell inserts (growth area of $1.12 \mathrm{~cm}^{2}$ and $0.4 \mathrm{~mm}$ pore size) at a density of 100,000 cells per transwell (Corning Inc., Tewksbury, MA). Chen's medium was replaced every 2 days over the course of the experiment. TEnR was measured every 4 days using the EVOM2 Epithelial VoltOhmMeter (WPI, Sarasota, FL) over the course of 20 days. Immortalized HCEnC-21T cells $^{31}$ were used as a positive control, whereas an empty FNC-coated transwell served as a background control. TEnR values for every time point represented the average of two wells with each well measured three times.

\section{Statistical Analysis}

All assays were performed for a minimum number of three independent experiments. A two-tailed Student's $t$-test was performed as indicated, and $P<0.05$ was considered statistically significant. For CFE, CDT, and RT-PCR experiments, the difference between groups were measured with one-way analysis of variance with Tukey's Multiple Comparison Test in GraphPad Prism version 4 (GraphPad Software, San Diego, CA) with $P<0.05$ considered as significant.

\section{Results}

Identification of Highly Proliferative Cell Colonies from Normal and FECD Donors

Even though rapid cellular senescence is commonly observed with HCEnCs, phenotypic heterogeneity of HCEnC primary cultures has been noted when designing cell therapy protocols. ${ }^{32}$ To investigate the effect of culture protocols on morphologic differences in cultured HCEnCs, a series of primary cultures from different donors were investigated. Morphologically distinct subpopulations of highly uniform cells growing in colony-like structures, interspersed among largely nonproliferative and senescent primary cells, were detected in representative normal corneas from a 21-year-old man, 56-year-old man, and 70-year-old man (HCEnC-21M, HCEnC-56M, and HCEnC-70M, respectively) (Figure 1, $\mathrm{A}-\mathrm{C}$ ). These distinct subpopulations consisted of small, regularly shaped hexagonal cells that did not exhibit the elongated fibroblast-like morphologic structure of slowly proliferative primary cells (Figure 1, A-C). We selectively isolated the highly proliferative colonies and continued to passage the cells, avoiding contamination with senescent cells by monitoring cellular morphology. We were able to passage the cells from all three donors beyond 80 passages; the cells grew continuously in regularly shaped hexagonal monolayers and exhibited contact inhibition in early (10 to 15 ) and late (80 to 85) passages without showing signs of senescence (Figure 1, D-I). The fibroblast-like HCEnCs from all three donors senesced after several passages.

We have previously used a SF assay to isolate cells that have an enhanced self-renewal capacity and differentiation potential. ${ }^{29}$ The colonies of both early- and late-passage cells developed into spheres by day 7 (Figure 1, J-L), 


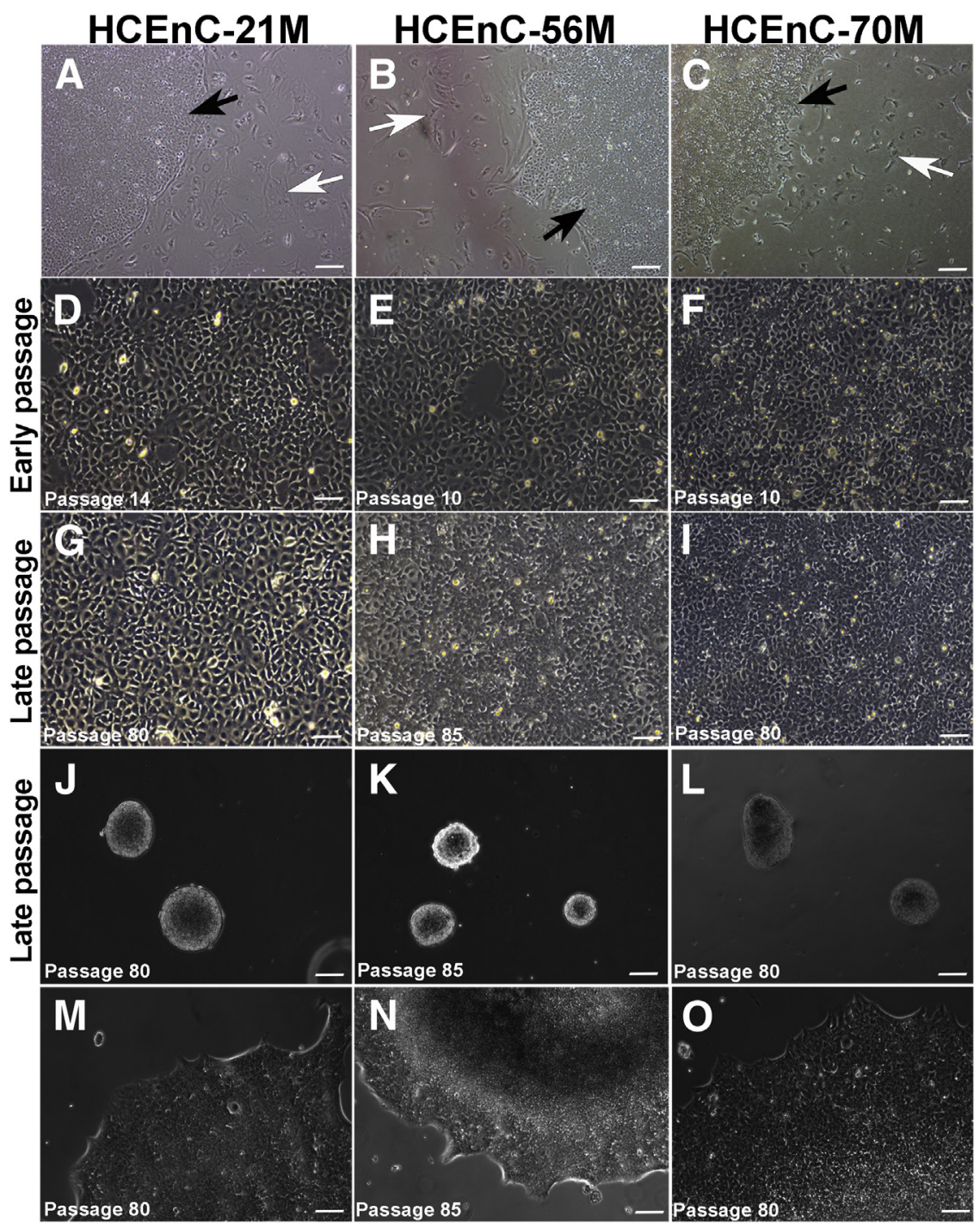

Figure 1 Ex vivo expansion of normal HCEnCs harbors progenitor-like subpopulation with distinct growth characteristics. A-C: Phase-contrast micrographs of two morphologically distinct subpopulations of highly proliferative HCEnCs (black arrows) and slow proliferating fibroblast-like HCEnCs (white arrows) generated from three normal donor corneal specimens from men 21 years (A), 56 years (B), and 70 years $(\mathbf{C})$ of age. D-I: Phase-contrast micrographs of the highly proliferative subpopulation within HCEnCs at early passage (D), 56M (E), and 70M (F) and late passage (G), 56M (H), 70M (I). J-0: Phase-contrast micrographs of spheres formed by HCEnCs at 7 days after seeding in SF medium ( $\mathbf{J}-\mathbf{L})$ and leading edge of the spheres from three normal donor HCEnCs at day 7 on $1 \%$ Matrigel (M-0). Scale bars $=100 \mu \mathrm{m}(\mathbf{A}-\mathbf{0})$. HCEnC, human corneal endothelial cell; SF, sphere formation.

indicating the presence of the self-aggregating potential seen in progenitor cells, ${ }^{31}$ whereas the fibroblastic cells remained adherent to the culture plates and died (Figure 1, A-C). Previous studies described SF as a process of in vitro formation of a SC niche in skin-derived neural crest progenitors. ${ }^{33}$ From this observation, we further investigated SC characteristics of the sphere-forming HCEnCs by culturing them on $1 \%$ Matrigel and allowing them to proliferate into monolayers of fusiform and compact cell colonies (Figure 1, M-O). Sphere-forming capacity did not differ between early and late passages and provided an ample source of cells for further marker and differentiation potential assays.

Moreover, a similar population of highly proliferative cells was identified in a primary culture from a 69-year-old female donor affected by FECD (F-HCEnC-69M) (Supplemental Figure S1 and Figure 2, A-C). The primary cells tended to be more senescent than those from normal donors and died in the second passage. In contrast, a subpopulation of highly proliferative cells from donor
F-HCEnC-69M formed spheres, could be passaged more than 45 times, and formed compact hexagonal monolayers that were not characteristic of dystrophic and fibroblastic FECD cells (Figure 2, D and E).

\section{Expression of Neural Crest Markers in Normal and FECD Progenitors}

Because HCEnCs are derived from neural crest cells, we next evaluated the expression of neural crest progenitor genes involved in neural crest development ${ }^{33}$ in HCEnC21M, -56M, -70M, and F-HCEnC-69M. To determine whether continued passaging alters cellular phenotype as previously described in a subpopulation of endothelial progenitors, ${ }^{6,13}$ neural crest marker expression was compared between early (10 to 15$)$ and late (70 to 75$)$ passages before induction of SF. For F-HCEnC-69M, passage 10 and passage 45 were compared. A nerve growth factor receptor or a low-affinity neurotrophin receptor $\left(\mathrm{p} 75^{\mathrm{NTR}}\right)^{26}$ has been used as a NCSC marker. In addition, 

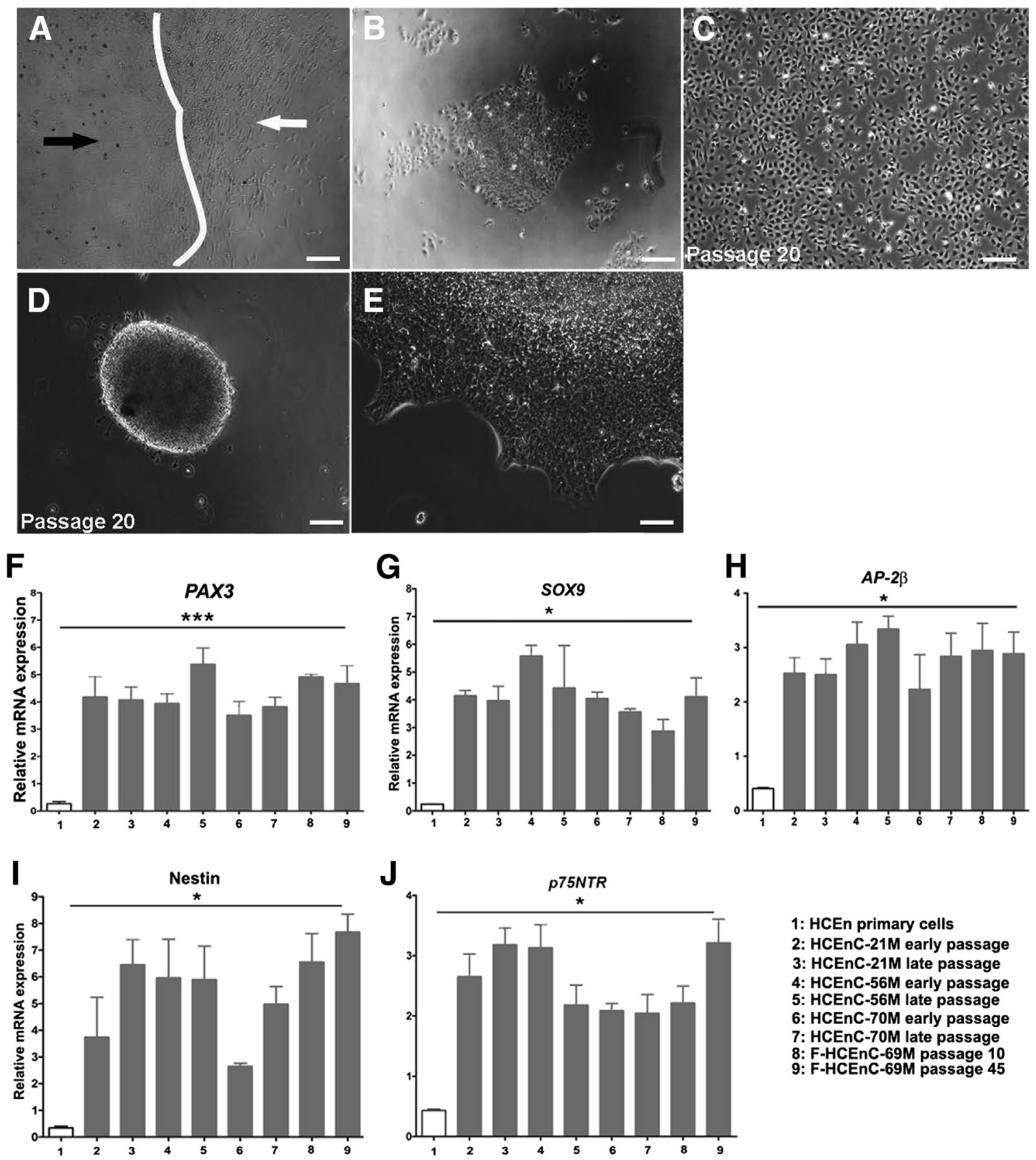

Figure 2 Elevated expression of neural crest-derived progenitor markers in FECD and normal HCEnCs compared with slow proliferating cells. A: Phasecontrast micrograph showing two morphologically distinct subpopulations of cells (white arrow, fibroblast-like cells with reduced proliferation; black arrow, rapidly proliferating cells), cultured from FECD ex vivo specimen (69-year-old man, designated as F-HCEnC-69M). B: Rapidly proliferating progenitor subpopulations of cells separated from slow dividing primary cells shown in $\mathbf{A}$ at 3 days after seeding. C: Progenitor population shown in $\mathbf{B}$ was trypsinized at day 6 and cultured for 5 days. D and E: Phase-contrast micrographs of sphere formation (D) and leading edge of sphere (E) by F-HCEnC-69M at passage 10. F-J: Gene expression analysis of neural crest-derived progenitor cell markers $\left(P A X 3\right.$, SOX9, AP-2 $\beta$, Nestin, and $\left.p 75^{N T R}\right)$ by real-time PCR in early and late passage HCEnCs derived from three normal donors and one FECD specimen. The relative expression of all markers in each cell type was compared with the mean expression of two normal and one FECD slow dividing primary cells. The early (passage 10 to 15 ) and late (passage 70 to 75 ) samples, except the early passage FECD samples which were derived between passages 10 to 16 . RT-PCR shows significantly higher expression in HCEnCs at early and late passages than primary HCEnC, $P A X 3$, Nestin, SOX9, and AP-2 $\beta$. Data are expressed as means \pm SEM. $n=3$ experiments. ${ }^{*} P<0.05,{ }^{*} * *<0.001$ by one-way analysis of variance. Scale bars $=100 \mu \mathrm{m}(\mathbf{A}-\mathbf{E})$. FECD, Fuchs endothelial corneal dystrophy; HCEnC, human corneal endothelial cell.

other studies have reported $P A X 3, \mathrm{AP}-2 \beta$, Nestin, and SOX 9 as markers of NCDP cells. ${ }^{22,34,35}$ The relative expression of PAX3, SOX9, AP-2 $\beta$, p $75^{\mathrm{NTR}}$, and Nestin mRNA was higher in all four subpopulations of HCEnCs (HCEnC-21M,
$-56 \mathrm{M},-70 \mathrm{M}$, and F-HCEnC-69M) that in the nondividing primary cells $(P<0.05)$ (Figure $2, \mathrm{~F}-\mathrm{J})$. The relative expression of these neural crest markers did not reveal any donor age- or passage-related differences. Interestingly, 
F-HCEnC-69M had neural crest marker expression levels comparable with those of normal donors. Taken together, the formation of spheres and expression of neural crest progenitor markers suggested that the highly proliferative subpopulations of HCEnCs were potentially NCDP cells.

\section{Proliferative Capacity and CFE}

In culture, adult HCEnCs routinely undergo one or two population doublings ( 2 to 10 passages $)^{14,36,37}$ in vitro and rapidly become senescent or undergo endothelial-tomesenchymal transition to a fibroblastic phenotype. To further quantify the growth capacity and the ability to form colonies as a functional assay of NCDP cells, different passages of HCEnC-21M, -56M, -70M, and F-HCEnC-69M were evaluated. The CDT of nondividing primary cells was
$83 \pm 7.2$ hours, whereas all NCDPs showed a much lower CDT, ranging from 31 to 48 hours $(P<0.0001)$ (Figure $3 \mathrm{~A})$. Pairwise comparisons of early- and late-passage CDTs showed significant differences in HCEnC-56M $(P<0.01)$ and $-70 \mathrm{M}(P<0.05)$ but not in HCEnC-21M, suggesting a reduced proliferative capacity of NCDPs in older adults (Figure 3, C and D). Analogous to NCDPs from normal donors, NCDPs from F-HCEnC-69M also displayed a lower CDT (32 \pm 0.6 hours) than that of slowly proliferative FECD primary cells $(753 \pm 107$ hours; $P=0.0003)$ (Figure 3B). These observations further support the classification of these cells as NCDPs but predict an age- and passage-dependent decline in their proliferative capability.

To evaluate the SC function of NCDPs before sphere formation, we calculated the average CFE between early and late passages and compared it with the CFE of slowly
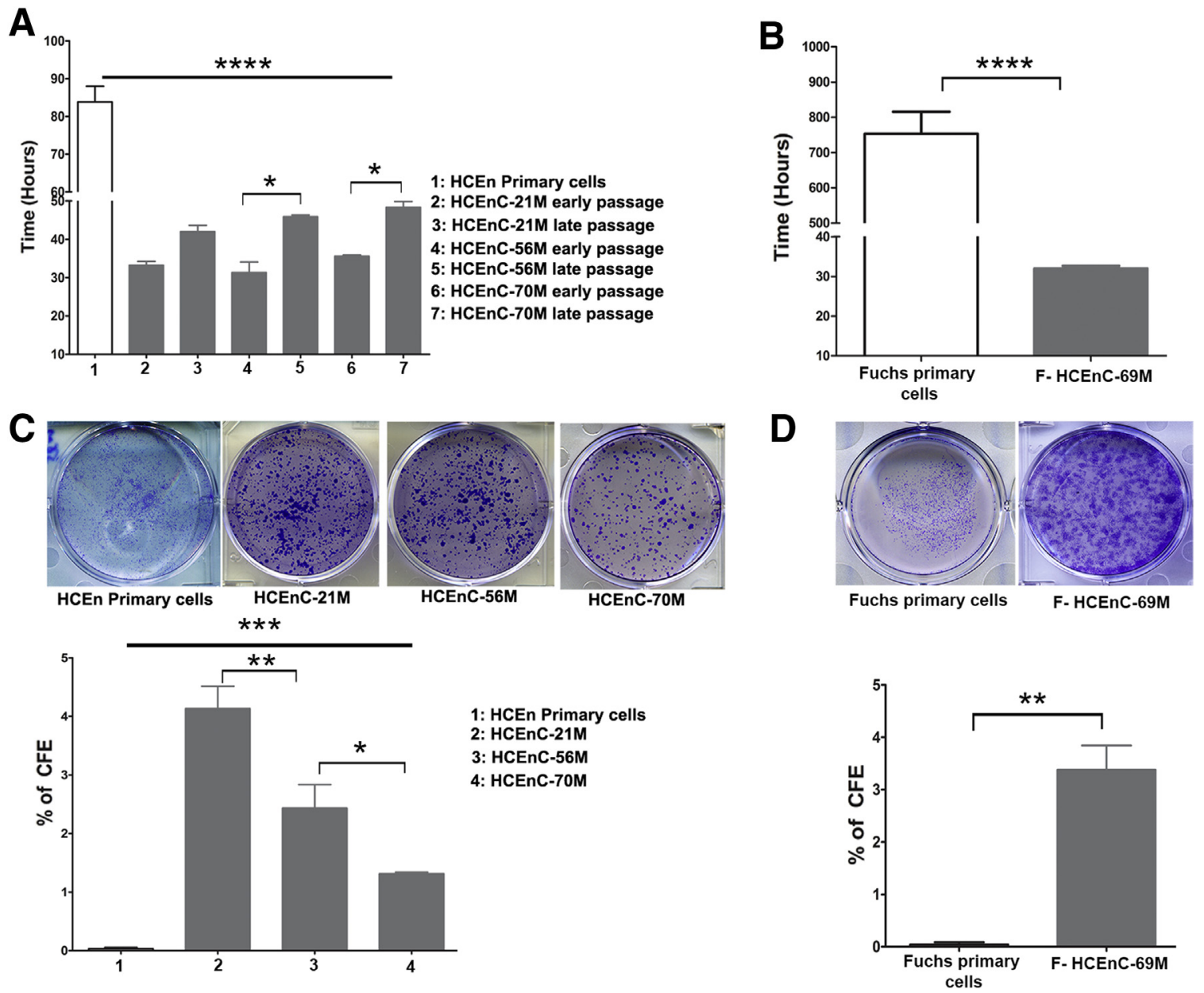

Figure 3 Cell proliferation and CFE of normal and FECD-derived progenitors is retained with age and passaging. A: CDT was calculated by seeding 50,000 cells per well in 12-well plates and counted after 2, 3, and 4 days using a Countess Cell Counter. Graph represents the CDT for early (10 to 15) and late (68 to 72) passages of HCEnC-21M, early (10 to 15) and late (70 to 75) passages of HCEnC-70M and early (9 to 14 ) and late (67 to 74) passages. HCEnC-56M and -70M show a higher proliferation rate at early passages than late passages; however, no significant difference is observed in proliferation of HCEnC-21M at higher passage. Primary corneal endothelial cells show a significantly slower proliferation. B: F-HCEnC-69M (passage 10 to 13) shows a higher proliferation rate with CDT of 32 hours than the slow proliferating cells from Fuchs tissue. C: The CFE of all three corneal endothelial progenitors quantified at earlier (10 to 14$)$ and late (65 to 75) passages shows an age- and passage-dependent reduction in their colony forming ability. D: Quantification and CFE of early passage (10 to 13 ) F-HCEnC-69M shows an increased efficacy compared with the primary cells derived from FECD specimen. Data are expressed as means \pm SEM. $n=4($ C); $n=3$ experiments $(\mathbf{A}, \mathbf{B}$, and $\mathbf{D})$. ${ }^{*} P<0.05,{ }^{* *} P<0.01,{ }^{* * *} P<0.001$, and ${ }^{* * * *} P<0.0001$ by one-way analysis of variance. CDT, cell doubling time; CFE, colony forming efficacy; FECD, Fuchs endothelial corneal dystrophy; HCEnC, human corneal endothelial cell. 
proliferating primary cells from normal and FECD donors. The average CFE of HCEnC-21M, $-56 \mathrm{M}$, and $-70 \mathrm{M}$ was $4.13 \% \pm 0.9 \%, 2.43 \% \pm 0.9 \%$, and $1.36 \% \pm 0.09 \%$, respectively (Figure 3C); all donors exhibited significantly higher CFE $(P=0.0001)$ than primary slowly proliferating cells, which did not form discernable colonies during the assay. Interestingly, there was a gradual decrease in CFE with increasing donor age (HCEnC-21M versus HCEnC56M, $P<0.005$; HCEnC-56M versus HCEnC -70M, $P<0.05$ ) (Figure 3C). The CFE of NCDPCs from F-HCEnC-69M was comparable with the CFEs of normal cells at $3.3 \% \pm 0.8 \%$ and was significantly higher than the CFE of slowly proliferating FECD primary cells $(P=0.0020)$ (Figure 3D), suggesting that NCDPCs from the FECD specimen were functionally indistinguishable from those that came from normal donors.

\section{Corneal Endothelial-Derived NCDPs Express Pluripotent Markers}

NCDPs are known to express pluripotency markers. ${ }^{33} \mathrm{We}$ next evaluated whether CEnCs express pluripotency-related genes in addition to neural crest markers. The endothelial NCDP cells produced readily detectable mRNA levels of $p 63$, OCT4, LGR5, and SOX2 with significantly higher levels than those found in primary slowly proliferating HCEnCs $(P<0.0001)$ (Figure 4, A-D). To evaluate whether passaging affects SC characteristics, SF was induced in early and late passages, and the expression of pluripotency-related transcripts was compared. The expression of p63, OCT4, $L G R 5$, and SOX2 was lower at late passages of HCEnC-21M and $-70 \mathrm{M}$ than early passages $(P<0.0001)$. However, this trend was not observed in HCEnC-56M (Figure 4, A-D). Note that the relative expression of p63, OCT4, and LGR5 was significantly higher in early passage HCEnC-21M than other NCDPs $(P<0.0001)$, indicating that the age of the donor might be important in determining the pluripotency of the cells (Figure 4, A-D). To further evaluate pluripotency markers in endothelium, we compared protein levels and localization of SSEA4, TRA-1-60, LGR5, and OCT4 by immunofluorescence staining of NCDPs from early and late passages. The fluorescence intensities of SSEA4 and TRA-160 were lower in late passages of all donors but did not significantly differ with the age of the donor (Figure 4, F and G). The intensity of LGR5 was lower in HCEnC-70M than in HCEnC-56 and $-21 \mathrm{M}$, but passaging did not seem to have noticeable effects on the protein levels of the HCEnC-56M donor, consistent with the mRNA data. OCT4, which is an embryonic SC marker, showed extensive nuclear localization in early and late passages of HCEnC-21M, but only in the early passages of HCEnC-56M. The HCEnC-70M donor had significantly diminished OCT4 staining, indicating that age might be a factor in adult SC maintenance (Figure 4, F and G).

Similar to normal donors, FECD-derived NCDPs also expressed relatively high levels of SC markers p63, OCT4, LGR5, and SOX2, whereas the primary FECD cells exhibited undetectable levels (Figure 4E). Immunofluorescence revealed bright staining with SSEA4, LGR5, and OCT4, comparable with the levels seen in normal NCDPs. However, TRA-1-60 levels were lower in intensity in FECDs than in normal donors. Moreover, although F-HCEnC-69M expressed LGR5 abundantly, we observed a stark difference in the staining pattern of LGR5 in FECDs compared with normal donors. In normal donors, LGR5 had diffuse intracellular and plasma membrane staining, ${ }^{13}$ whereas in FHCEnC-69M it had discrete punctate staining that was mostly intracellular without clear binding of the plasma membrane (Figure 4H). Internalization of LGR5 into the Golgi complex has been described because of Wnt signaling activation. ${ }^{38}$

Taken together, corneal endothelial NCDPs expressed pluripotency markers, similar to neural crest progenitors in skin and other organs. ${ }^{28,33,39}$ It is possible that in HCEnCs there is progressive reduction in stemness with age, leading to decreased self-renewal potential as shown with changes in CDT and CFE.

\section{NCDPs Differentiate to Neuronal and CEnCs}

To further assess the multipotency of endothelial progenitor cells, we evaluated NCDP cell potential to differentiate into neuronal and corneal endothelial cell lineages in vitro. After normal and FECD neuropsheres of early and late passages were dissociated and cultured in neural induction medium for 7 days, single cells started forming neurite-like processes and having morphologic features consistent with bipolar and multipolar neurons (Figure 5). Immunofluorescence microscopy revealed staining of the intermediate neuronal marker $\beta$-III tubulin, mature neuronal marker microtubule-associated protein 2 , and astrocyte-specific marker glial fibrillary acidic protein ${ }^{40,41}$ throughout the cytoplasm of the normal and FECD cells (Figure 5). Marker staining patterns did not differ with age or between early and late passages of NCDPs (data not shown). These markers were undetected in undifferentiated NCDPs (Supplemental Figure S2). Adult NCDP differentiation into neural lineages in vitro has been shown with skin-derived progenitors and corneal derived-neural crest cells. ${ }^{28,33}$

In parallel, early and late passages of NCDP cells were cultured in CEnC differentiation medium (Chen's medium) ${ }^{30}$ for 6 days and formed a uniform hexagonal endothelial cell monolayer, which did not undergo endothelial mesenchymal transition with passaging. The differentiated cells produced endothelial cell markers such as $\mathrm{Na}^{+} / \mathrm{K}^{+}$ATPase, which mainly localized to the basolateral membrane (Figure 6A), and ZO-1, which localized to the cell-cell junctions (Supplemental Figure S3). Interestingly, the production of $\mathrm{p} 75^{\mathrm{NTR}}$ was retained in the differentiated cells, but it was not present in the primary cells that were not differentiated from NCDPs (Figure 6A). To further evaluate if these differentiated cells displayed the functional characteristics of HCEnCs, we tested the barrier integrity by measuring TEnR. HCEnCs have been shown to establish a TEnR of 15 to $25 \Omega \mathrm{cm}^{2}$ in vitro. ${ }^{31}$ Figure 6B illustrates the TEnR measured in early- and late-passages of differentiated HCEnC-21M, -56M, -70M, and 
A
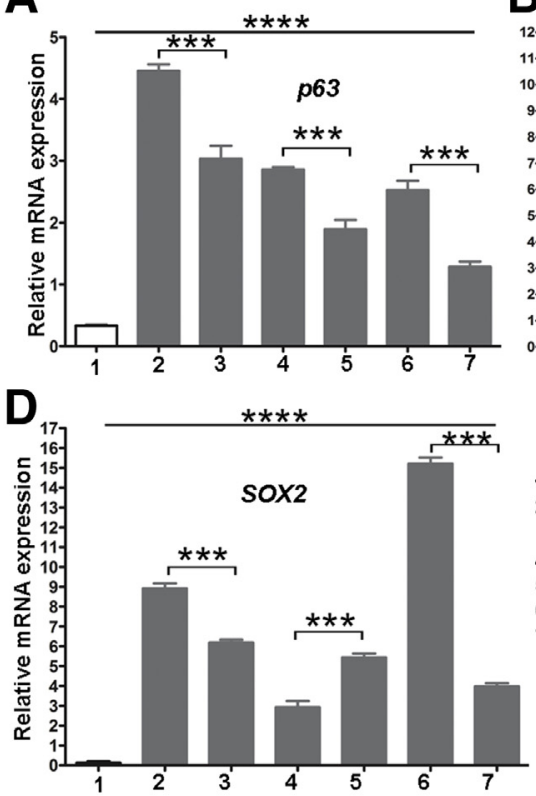

B
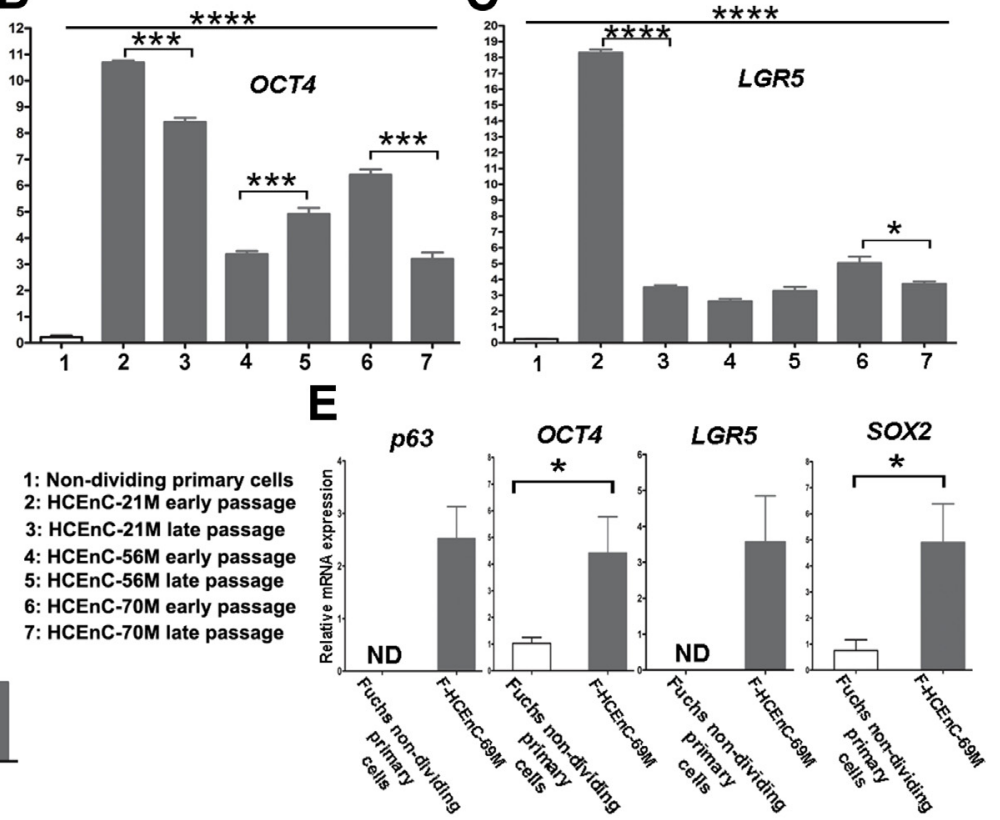

E

1: Non-dividing primary cells 3: HCEnC-21M late passage 4: HCEnC-56M early passage 5: HCEnC-56M late passage 6: HCEnC-70M early passage 7: HCEnC-70M late passage
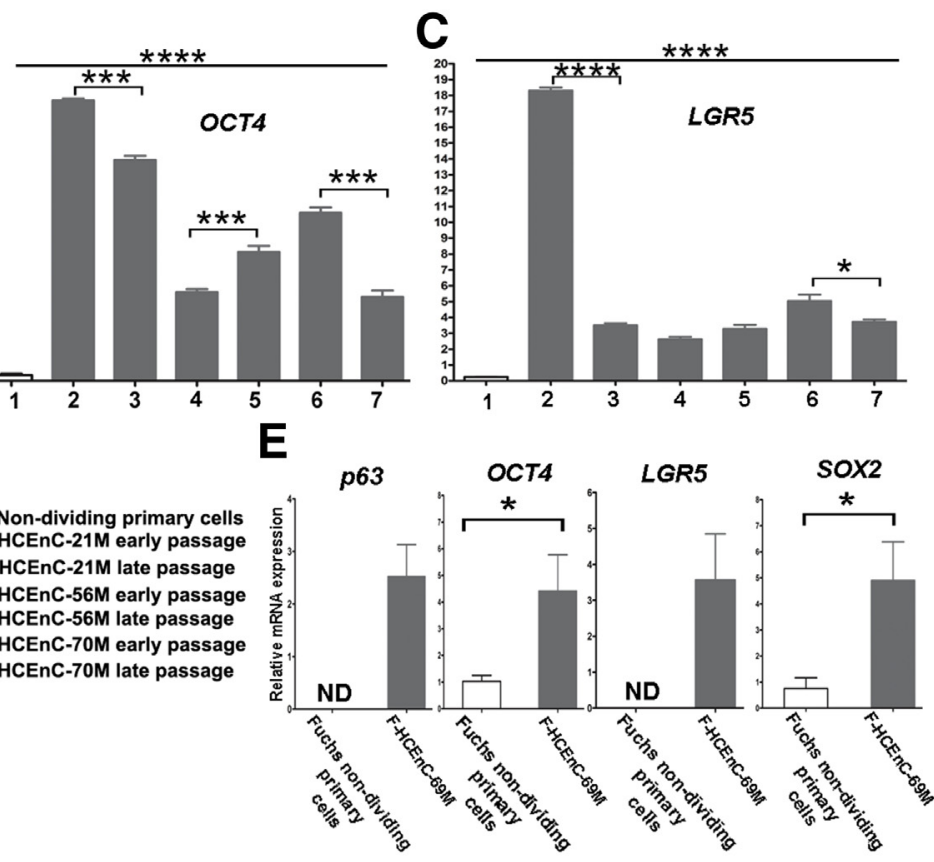

F

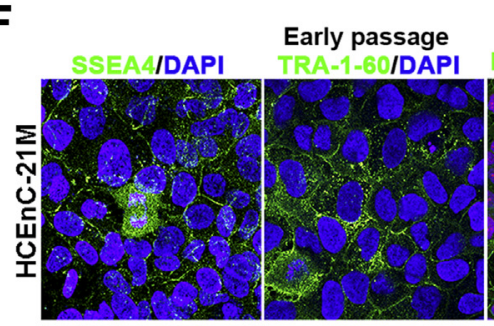

\section{G}
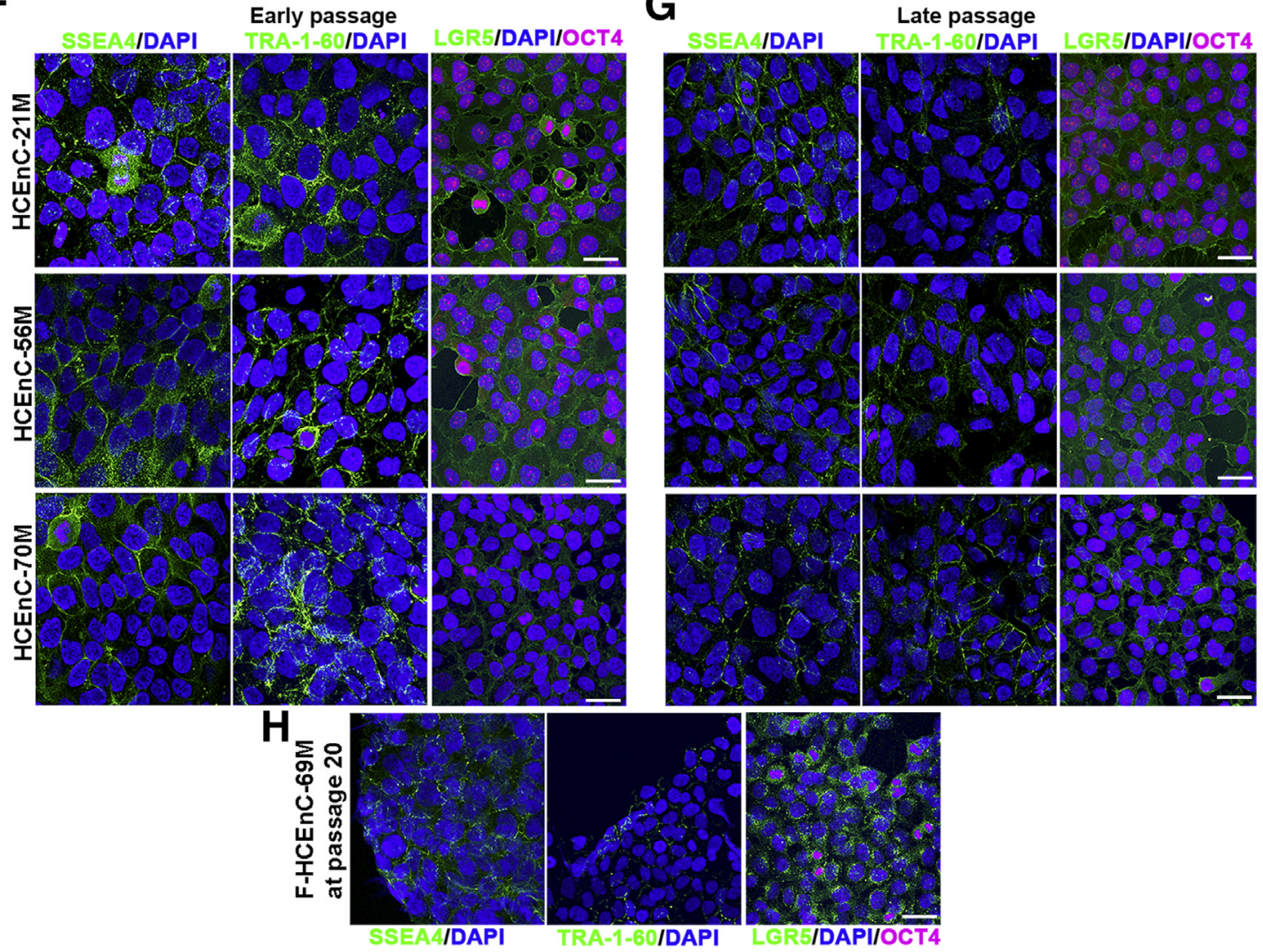

Figure 4 Normal donor- and FECD specimen-derived progenitors express characteristic pluripotent markers. A-D: Spheres were generated from NCDPs on a $1 \%$ Matrigel-coated surface and tested for differential expression of stem cell markers. Relative expression of p63, OCT4, LGR5, and SOX2 are significantly higher in all progenitors irrespective of age and passage than nondividing primary HCEnCs. E: Spheres generated from F-HCEnC-69M (passage 15 to 24 ) show significantly higher relative expression of OCT4, SOX2, LGR5, and p63 than Fuchs nondividing cells (relative expression was below $C_{T}$ ). $\mathbf{F}$ and $\mathbf{G}$ : Spheres generated from early (F) and late (G) passage normal donor NCDPs were stained for SSEA4, TRA-1-60, LGR5, and 0CT4. The expression of SSEA4 and TRA-1-60 decreases with passage, whereas both LGR5 and OCT4 show a reduced expression in HCEnC-56M and -70M. H: Spheres generated from early passage F-HCEnC69M cells express stem cell markers SSEA4 and 0CT4 similar to early passage HCEnC-56M and -70M. TRA-1-60 shows a reduced expression compared with all three cell types in F. LGR5 shows an intracellular localization that differs from HCEnC-21M and -56M. Data are expressed as means \pm SEM. $n=6$ experiments $(\mathbf{A}-\mathbf{E}) .{ }^{*} P<0.05,{ }^{* * *} P<0.001,{ }^{* * * * P}<0.0001$ by two-tailed Student's $t$-test for F-HCEnC-69M and one-way analysis of variance for the others. Scale bars $=100 \mu \mathrm{m}$. FECD, Fuchs endothelial corneal dystrophy; HCEnC, human corneal endothelial cell; NCDP, neural crest-derived progenitor; ND, not detected. 


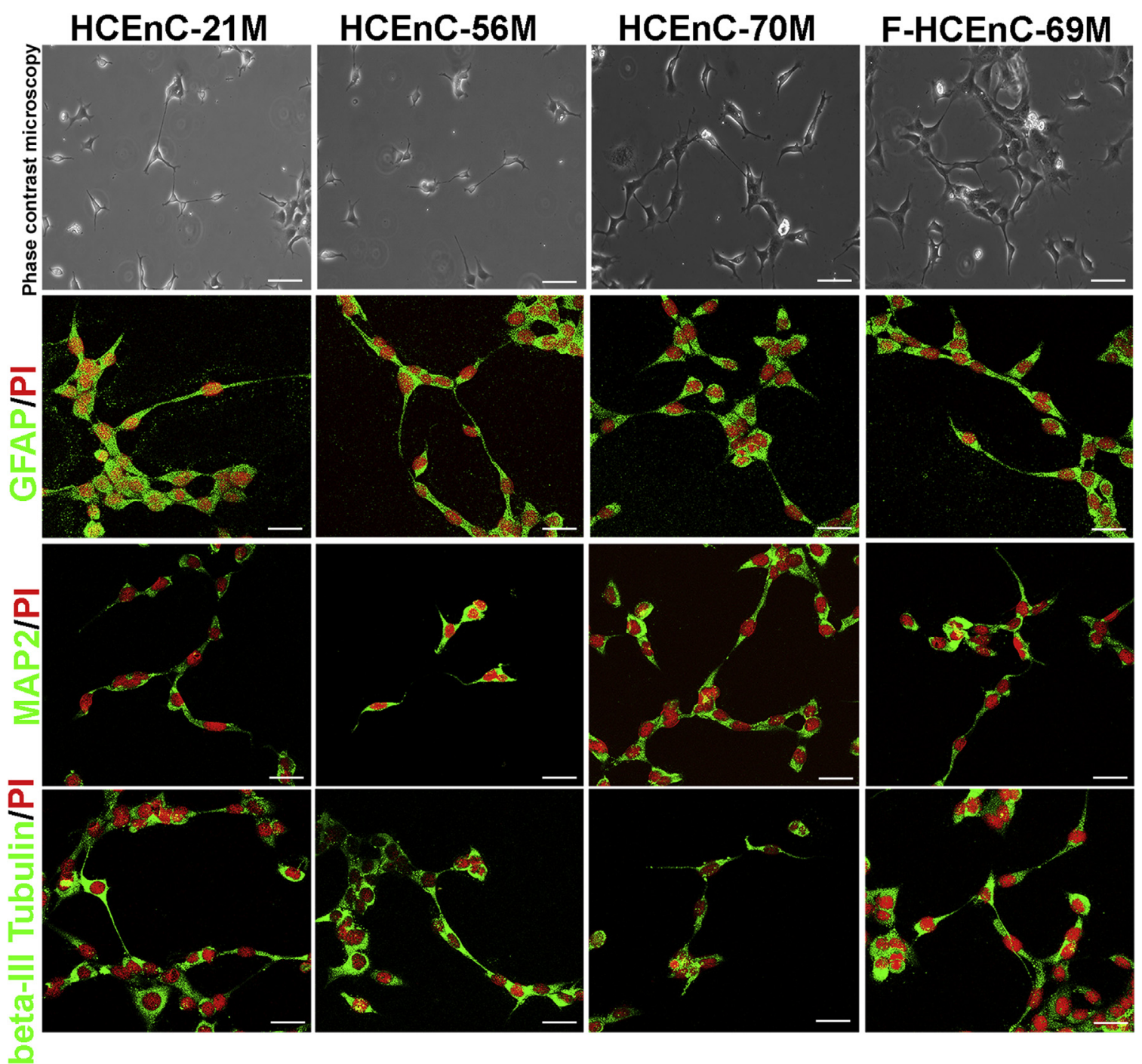

Figure 5 Normal and FECD-derived progenitors can undergo differentiation to neuronal lineage. Late-passage NCDPs generated after trypsinization of spheres were seeded at a density of $2.5 \times 10^{4}$ cells $/ \mathrm{cm}^{2}$ on glass coverslips coated with $100 \mu \mathrm{g} / \mathrm{mL}$ poly-d lysine and $20 \mu \mathrm{g} / \mathrm{mL}$ laminin. Cells were differentiated with neural induction media for 7 days, and immunofluorescence was performed for GFAP, MAP2, and $\beta$-III tubulin. HCEnC-21M, 56M, 70M, and F-HCEnC-69M express neuronal markers suggestive of differentiation to neuronal lineage. Scale bars $=100 \mu \mathrm{m}$. FECD, Fuchs endothelial corneal dystrophy; GFAP, glial fibrillary acidic protein; HCEnC, human corneal endothelial cell; MAP2, microtubule-associated protein 2; NCDP, neural crest-derived progenitor; PI, propidium iodide.

F-HCEnC-69M measured over the course of 20 days. The initial TEnR (day 2), measured between 6 and $9 \Omega \mathrm{cm}^{2}$, followed by a steep initial increase $\left(10\right.$ to $\left.13 \Omega \mathrm{cm}^{2}\right)$ during the first 12 days and peaked between 11 and $15 \Omega \mathrm{cm}^{2}$. This pattern of TEnR in vitro was similar to that of previously published TEnR values. ${ }^{31,42}$ No significant differences in TEnR were detected between any NCDPs at early and late passages. These data demonstrate the differentiation capability of adult NCDPs to $\mathrm{CEnCs,}$ which retain their functional competence.

\section{Discussion}

Although endothelial cells are thought to be arrested in the postmitotic state in humans, recent reports present evidence of cell proliferation during surgical injury or disruption of contact inhibition, supporting the role of purported SCs in endothelial self-renewal. ${ }^{43,44}$ Specifically, spontaneous regrowth of endothelium and clearing of central corneal edema has been described in cases whereby DM was removed without implantation of healthy donor endothelium $^{45}$ and when nonfunctional or detached transplants were left in FECD eyes after removal of the diseased central endothelium. ${ }^{46,47}$ These clinical observations indicate a capacity for mitotic expansion not only of normal corneal endothelium but also of FECD corneal endothelium. Herein, we present the evidence that the source of this regrowth capacity partially stems from the NCDPs that form unique small, hexagonal, highly proliferative, and phenotypically distinct populations of cells without signs of senescence and 


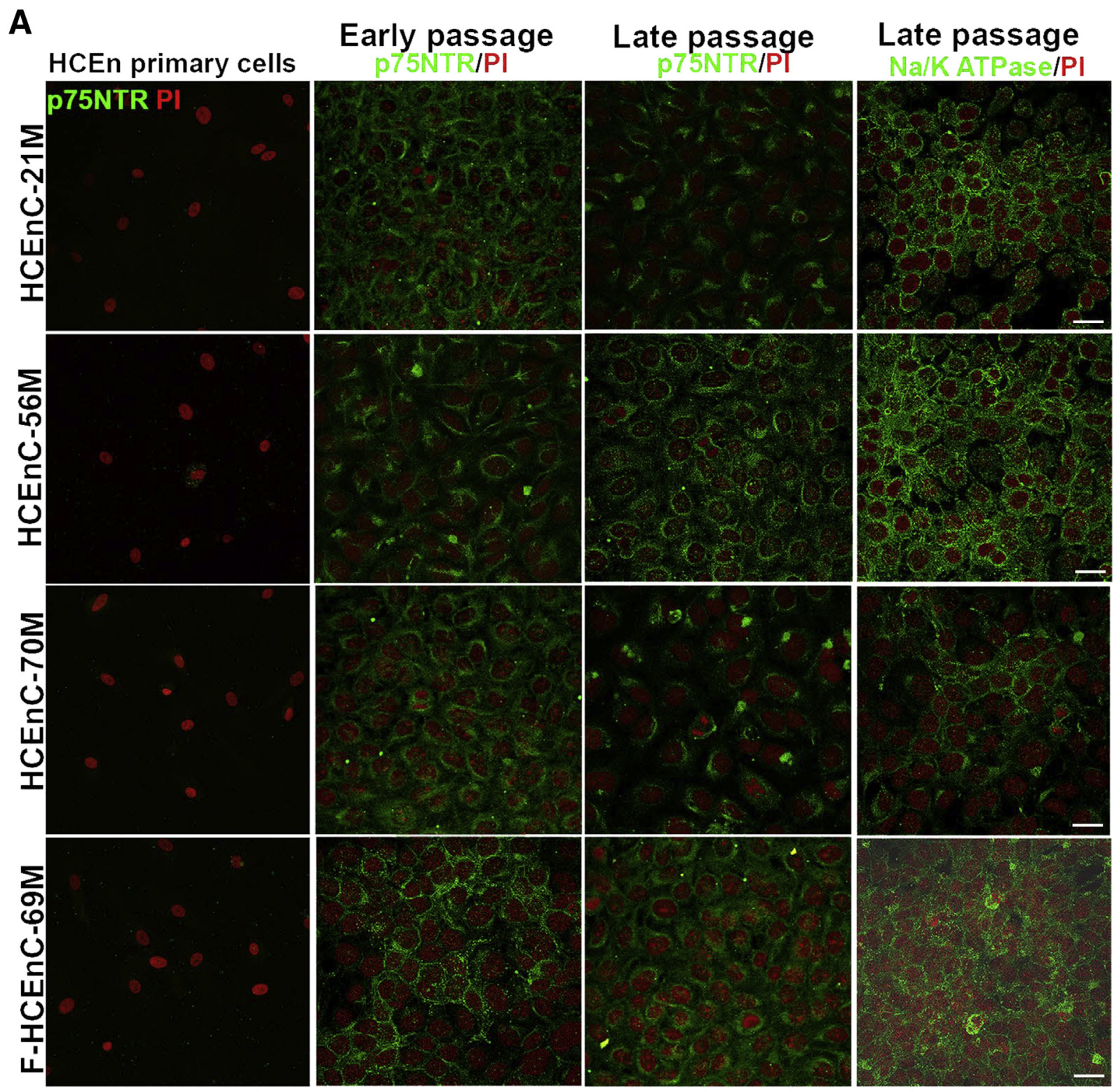

B

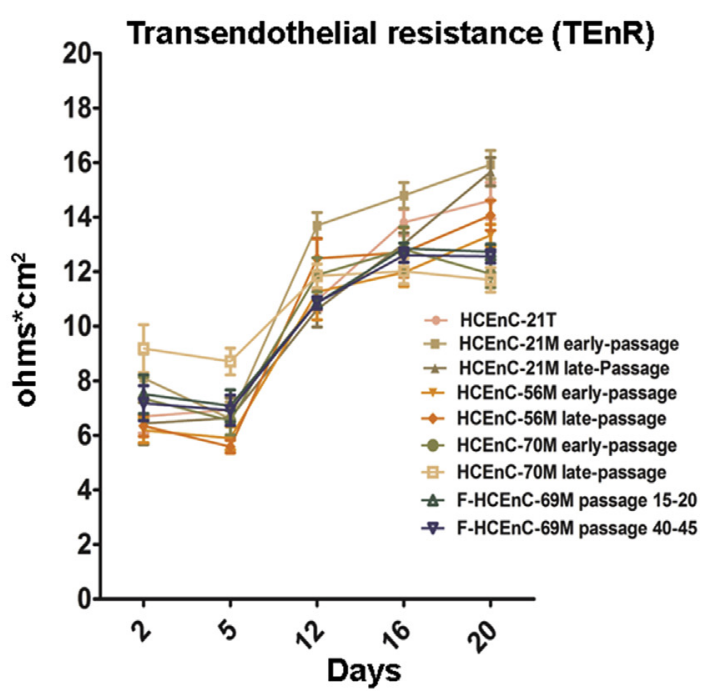

Figure 6 NCDPs differentiate into corneal endothelium that retains p75-positivity in vitro. A: Spheres generated from early and latepassage NCDP cells were trypsinized and cultured on FNC-coated coverslips and allowed to differentiate for 6 days in Chen's medium. All NCDP cells express the neural crest marker $p 75^{\mathrm{NTR}}$ and $\mathrm{Na}^{+} / \mathrm{K}^{+}$ATPase that labels the corneal endothelium. Nondividing primary HCEnC were negative for $\mathrm{p} 75^{\mathrm{NTR}}$. B: NCDP cells derived from spheres were plated in 12-well transwell inserts $(0.4 \mathrm{~mm})$ at a density of 100,000 cells per transwell, and TEnR was measured every 4 days for 20 days. Note that HCEnC-21M, -56M, -70M, and F-HCEnC-69M establishes a typical corneal endothelial barrier that ranges between 10 and $13 \Omega \mathrm{cm}^{2}$ at 12 days that continues until 20 days. Previously established corneal endothelial cell line (HCEnC-21T) was used as positive control. The TEnR value for each time point represents the average of experiments. Data are expressed as means \pm SEM. $n=6$ experiments $(\mathbf{A}) ; n=3$ independent experiments with each experiment performed in duplicate (B). Scale bars $=100 \mu \mathrm{m}$. HCEnC, human corneal endothelial cell; NCDP, neural crest-derived progenitor; PI, propidium iodide; TEnR, transendothelial resistance. 
with a capacity to differentiate into other neural crest derivatives, such as neurons. Interestingly, the NCDP cells were identified in the endothelium of donors affected by FECD, indicating that the progenitors were spared by the dystrophic degeneration. These newly described cells hold the promise of being able to regenerate an individual's own endothelial cells, even in FECD.

Our study provides evidence that distinct subpopulations of highly uniform endothelial cells may represent neural crest-derived SCs that persisted into adulthood with their full potential normally restricted by the local microenvironment but revealed in culture (Figure 7). Contact inhibition, presence of transforming growth factor- $\beta$ in aqueous fluid, and lack of paracrine stimulation by cell-cycle-promoting growth factors were likely factors ${ }^{48}$ lifted in culture leading to the isolation and characterization of NCDP cells from normal and FECD donors (Figure 7). The novelty of our findings lies in the fact that we isolated the NCDP cells from the primary culture and subcultured them for $>70$ passages to date. Before performing the SF assay, we detected that the purported NCDP cells (from normal and FECD donors) had significantly greater CFEs along with shorter CDTs than primary endothelial cells. We found that CFE was greater in young donors than in older donors. It is possible that the NCDP cells of older donors have acquired oxidation-induced macromolecular damage that renders them more prone to be senescent. ${ }^{49}$ Nevertheless, the production of neural crest markers PAX3, SOX9, AP-2 $\beta$, Nestin, and $\mathrm{p} 75^{\mathrm{NTR}}$ and endothelial lineage-related proteins, along with TEnR, did not vary between early and late passages and was readily detected in F-HCEnC-69M. Moreover, the primary HCEnCs fated for senescence did neither stain with $\mathrm{p} 75^{\mathrm{NTR}}$ nor form spheres (Figure 7). Similarly, previous studies showed that $\mathrm{p} 75^{\mathrm{NTR}}$ is highly expressed in corneal endothelial progenitor cells and might be an important cell surface marker for isolation of progenitor cells from tissues. ${ }^{6,26}$ However, our study identified that there is a cooperative expression of pluripotency, neural crest, and endothelial lineage-related genes involved in the phenotypic footprint of the endothelial NCDP cells. In the niche of spheres in vitro, endothelial NCDP cells exhibited a transcriptional profile of pluripotent cells that persisted in high passages ( $>70$ passages), although some markers trended toward lower expression with older donors and higher passages, indicating possible epigenetic modifications of NCDP cells with increased passaging and donor age. Further corroborating their pluripotency, the HCEnC-21M, -56M, 70M, and F-HCEnC$69 \mathrm{M}$ cells were able to generate neural progeny in vitro as identified by glial fibrillary acidic protein, microtubuleassociated protein 2 , and $\beta$-III tubulin stains. This underscores the neural crest origin of the human endothelial progenitor cells, a finding that has not been described in the previous studies on endothelial SCs. ${ }^{6,11,13}$ Interestingly, the endothelial cell progeny of NCDPs retained the expression of $\mathrm{p} 75^{\mathrm{NTR}}$ and continued to proliferate without signs of senescence. This indicates that these cells are not yet terminally differentiated in vitro and might provide a source of constructs for regenerative therapies (Figure 7).

Of note, NCDPs were not affected by FECD. A main hallmark of FECD is the central formation of guttae and

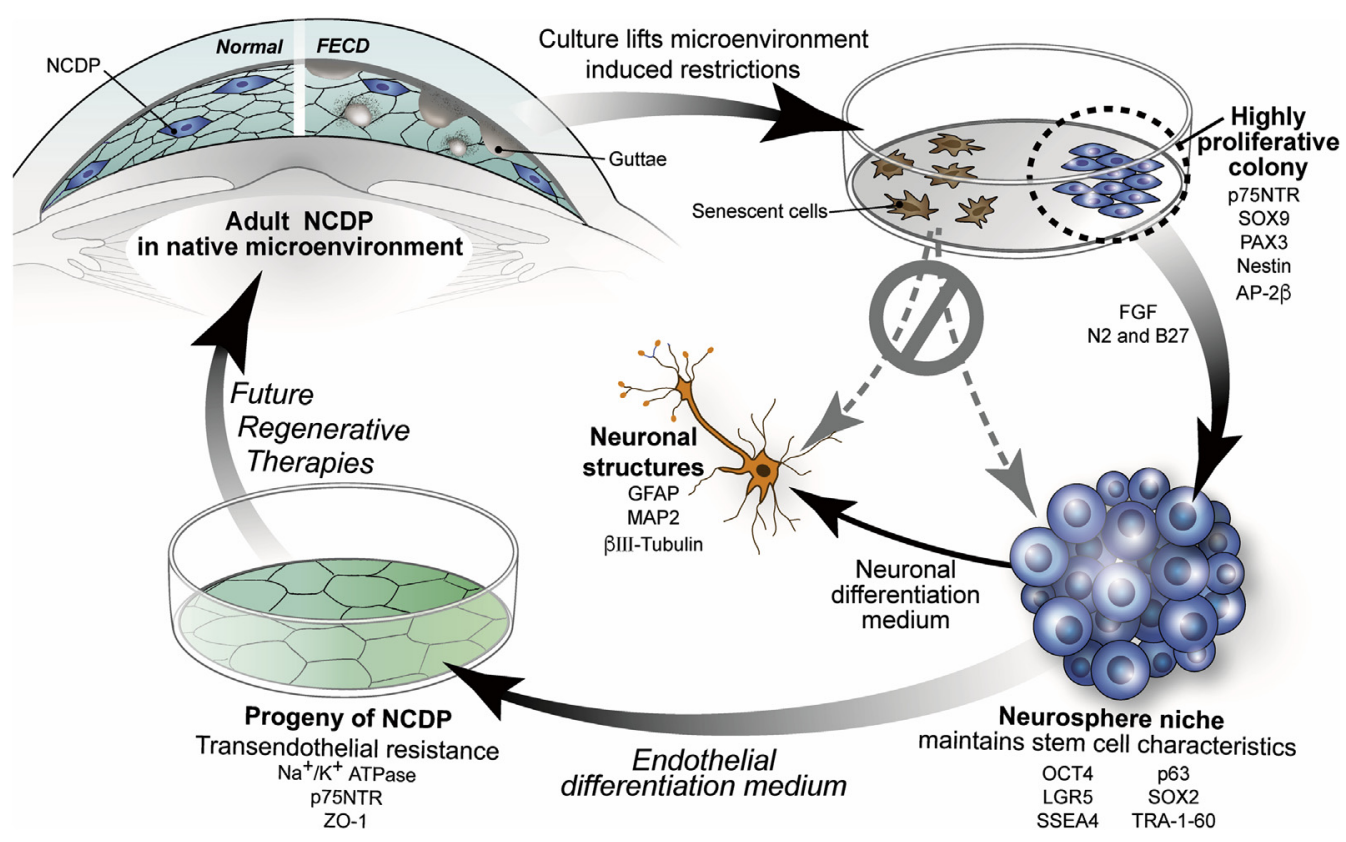

Figure 7 Diagram of the role of the adult NCDPs in endothelial cell renewal. Highly proliferative colonies isolated from normal and FECD corneal endothelium demonstrate expression of neural crest progenitor markers and propensity for neurosphere formation which fosters stem cell niche in vitro and promotes differentiation into neuronal structures and p75-positive differentiated endothelial cells, indicating a potential application for future regenerative therapies. FECD, Fuchs endothelial corneal dystrophy; FGF, fibroblast growth factor; GFAP, glial fibrillary acidic protein; MAP2, microtubule-associated protein 2; NCDP, neural crest-derived progenitor. 
endothelial cell loss in the early stages of the disease with progression of the same findings toward the periphery in the later stages. ${ }^{5,50}$ The central cornea is in the direct path of UV light, ${ }^{51}$ which causes epigenetic modifications in CEnCs and contributes to acquire DNA damage, which is known to account for the pathogenesis of FECD. ${ }^{52}$ It is likely that peripheral NCDPs were not yet affected by the oxidative stress-induced damage and thus were amenable to isolation and identification.

In the future, two main questions that need to be addressed are, first, can we identify the predominant location of the endothelial NCDP cells; and, second, what are specific factors in the local corneal microenvironment that restrict the potential of NCDPs. Our study suggests that NCDP cells are possibly interspersed throughout the endothelial mosaic because the normal NCDP cells were isolated from the whole corneas, whereas the FECD NCDP cells were retrieved from a surgical specimen of approximately $8 \mathrm{~mm}$ in size. Previous studies reported existence of progenitor-like cells at the peripheral zone in human corneal endothelium. ${ }^{7,9,13} \mathrm{He}^{\text {et }} \mathrm{al}^{7}$ elucidated the presence of the nonvisual periphery of the cornea, a renewal zone where endothelial cells divide very slowly and migrate toward the center, suggesting the specific niche located in the trabecular meshwork or in the transition zone. Moreover, HCEnCs identified through LGR5 expression exhibited stem/progenitor cell characteristics and were predominantly located in the peripheral zone of the cornea. ${ }^{13}$ Existence of a potentially common progenitor cell of corneal endothelium and trabecular meshwork, residing in the transitional zone between the two cell types ${ }^{7}$ needs further investigation, especially because trabecular meshwork cells share a neural crest origin with endothelium. ${ }^{7}$ Regarding the second question, we previously demonstrated up-regulation of cyclin D and CDK4 in highly proliferative HCEnCs, indicating that these factors are crucial in bypassing control mechanisms of cellular senescence and maintaining an endothelial phenotype. ${ }^{31}$ The growth modifying roles of $\mathrm{DM},{ }^{53}$ aqueous humor, ${ }^{54}$ and the limbal microenvironment ${ }^{7,29}$ are possible factors that contribute to the dormancy of NCDP cells in vivo. Further elucidation of the interplay between the local microenvironment, the NCDP cell niche, and the transcription factors involved in maintenance of NCDP cell stemness is important for understanding how to enhance propagation of endogenous endothelium in vivo.

\section{Conclusions}

We detected that an endothelial monolayer harbors NCDP cells that are capable of perpetual division and retain the potential to differentiate into other neural crest derivatives. The cooperative expression of pluripotency and neural crest marker genes contributes to the phenotypic footprint of the NCDP cells in normal donors and is preserved in FECD patients. This highly novel finding has a great impact on the clinical approach to FECD patients, whose endothelium is currently treated as being terminally and irreversibly damaged, requiring an allogeneic transplantation to provide a new source of cells. The finding of fairly normal NCDP cells in FECD opens a new area of research focusing on the retrieval and utilization of progenitors for autologous cell therapies in the future.

\section{Acknowledgments}

K.R.K. conceived and designed experiments; collected, analyzed, and interpreted data; and wrote the manuscript. T.S. conceived and designed experiments. F.W.P. acquired study materials. M.O.P. acquired study materials. U.V.J. conceived and designed experiments; provided funding; acquired study materials; collected, analyzed, and interpreted data; and wrote and approved the manuscript.

\section{Supplemental Data}

Supplemental material for this article can be found at http://dx.doi.org/10.1016/j.ajpath.2016.06.011.

\section{References}

1. Joyce NC: Proliferative capacity of the corneal endothelium. Prog Retin Eye Res 2003, 22:359-389

2. Bourne WM: Biology of the corneal endothelium in health and disease. Eye (Lond) 2003, 17:912-918

3. Dobbins KR, Price FW Jr, Whitson WE: Trends in the indications for penetrating keratoplasty in the midwestern United States. Cornea 2000, 19:813-816

4. Ghosheh FR, Cremona FA, Rapuano CJ, Cohen EJ, Ayres BD, Hammersmith KM, Raber IM, Laibson PR: Trends in penetrating keratoplasty in the United States 1980-2005. Int Ophthalmol 2008, 28:147-153

5. Schmedt T, Silva MM, Ziaei A, Jurkunas U: Molecular bases of corneal endothelial dystrophies. Exp Eye Res 2012, 95:24-34

6. Hara S, Hayashi R, Soma T, Kageyama T, Duncan T, Tsujikawa M, Nishida K: Identification and potential application of human corneal endothelial progenitor cells. Stem Cells Dev 2014, 23:2190-2201

7. He Z, Campolmi N, Gain P, Ha Thi BM, Dumollard JM, Duband S, Peoc'h M, Piselli S, Garraud O, Thuret G: Revisited microanatomy of the corneal endothelial periphery: new evidence for continuous centripetal migration of endothelial cells in humans. Stem Cells 2012, 30: 2523-2534

8. Yokoo S, Yamagami S, Yanagi Y, Uchida S, Mimura T, Usui T, Amano S: Human corneal endothelial cell precursors isolated by sphere-forming assay. Invest Ophthalmol Vis Sci 2005, 46: $1626-1631$

9. Whikehart DR, Parikh CH, Vaughn AV, Mishler K, Edelhauser HF: Evidence suggesting the existence of stem cells for the human corneal endothelium. Mol Vis 2005, 11:816-824

10. McGowan SL, Edelhauser HF, Pfister RR, Whikehart DR: Stem cell markers in the human posterior limbus and corneal endothelium of unwounded and wounded corneas. Mol Vis 2007, 13: 1984-2000

11. Noh JW, Kim JJ, Hyon JY, Chung ES, Chung TY, Yi K, Wee WR, Shin YJ: Stemness characteristics of human corneal endothelial cells cultured in various media. Eye Contact Lens 2015, 41:190-196 
12. Mimura T, Yamagami S, Yokoo S, Usui T, Tanaka K, Hattori S, Irie S, Miyata K, Araie M, Amano S: Cultured human corneal endothelial cell transplantation with a collagen sheet in a rabbit model. Invest Ophthalmol Vis Sci 2004, 45:2992-2997

13. Hirata-Tominaga K, Nakamura T, Okumura N, Kawasaki S, Kay EP, Barrandon Y, Koizumi N, Kinoshita S: Corneal endothelial cell fate is maintained by LGR5 through the regulation of hedgehog and Wnt pathway. Stem Cells 2013, 31:1396-1407

14. Peh GS, Toh KP, Wu FY, Tan DT, Mehta JS: Cultivation of human corneal endothelial cells isolated from paired donor corneas. PLoS One 2011, 6:e28310

15. Senoo T, Joyce NC: Cell cycle kinetics in corneal endothelium from old and young donors. Invest Ophthalmol Vis Sci 2000, 41: 660-667

16. Wilson SE, Lloyd SA, He YG, McCash CS: Extended life of human corneal endothelial cells transfected with the SV40 large T antigen. Invest Ophthalmol Vis Sci 1993, 34:2112-2123

17. Wilson SE, Weng J, Blair S, He YG, Lloyd S: Expression of E6/E7 or SV40 large T antigen-coding oncogenes in human corneal endothelial cells indicates regulated high-proliferative capacity. Invest Ophthalmol Vis Sci 1995, 36:32-40

18. Zaniolo K, Bostan C, Rochette Drouin O, Deschambeault A, Perron MC, Brunette I, Proulx S: Culture of human corneal endothelial cells isolated from corneas with Fuchs endothelial corneal dystrophy. Exp Eye Res 2012, 94:22-31

19. Haydari MN, Perron MC, Laprise S, Roy O, Cameron JD, Proulx S, Brunette I: A short-term in vivo experimental model for Fuchs endothelial corneal dystrophy. Invest Ophthalmol Vis Sci 2012, 53: 6343-6354

20. Tuft SJ, Coster DJ: The corneal endothelium. Eye (Lond) 1990, 4(Pt 3):389-424

21. Crane JF, Trainor PA: Neural crest stem and progenitor cells. Annu Rev Cell Dev Biol 2006, 22:267-286

22. Fernandes KJ, McKenzie IA, Mill P, Smith KM, Akhavan M, Barnabe-Heider F, Biernaskie J, Junek A, Kobayashi NR, Toma JG, Kaplan DR, Labosky PA, Rafuse V, Hui CC, Miller FD: A dermal niche for multipotent adult skin-derived precursor cells. Nat Cell Biol 2004, 6:1082-1093

23. Hunt DP, Morris PN, Sterling J, Anderson JA, Joannides A, Jahoda C, Compston A, Chandran S: A highly enriched niche of precursor cells with neuronal and glial potential within the hair follicle dermal papilla of adult skin. Stem Cells 2008, 26: $163-172$

24. Wong CE, Paratore C, Dours-Zimmermann MT, Rochat A, Pietri T, Suter U, Zimmermann DR, Dufour S, Thiery JP, Meijer D, Beermann F, Barrandon Y, Sommer L: Neural crest-derived cells with stem cell features can be traced back to multiple lineages in the adult skin. J Cell Biol 2006, 175:1005-1015

25. Hagedorn L, Suter U, Sommer L: P0 and PMP22 mark a multipotent neural crest-derived cell type that displays community effects in response to TGF-beta family factors. Development 1999, 126: $3781-3794$

26. Morrison SJ, White PM, Zock C, Anderson DJ: Prospective identification, isolation by flow cytometry, and in vivo self-renewal of multipotent mammalian neural crest stem cells. Cell 1999, 96: 737-749

27. Hatzistergos KE, Takeuchi LM, Saur D, Seidler B, Dymecki SM, Mai JJ, White IA, Balkan W, Kanashiro-Takeuchi RM, Schally AV, Hare JM: cKit + cardiac progenitors of neural crest origin. Proc Natl Acad Sci U S A 2015, 112:13051-13056

28. Yoshida S, Shimmura S, Nagoshi N, Fukuda K, Matsuzaki Y, Okano H, Tsubota K: Isolation of multipotent neural crest-derived stem cells from the adult mouse cornea. Stem Cells 2006, 24: $2714-2722$

29. Katikireddy KR, Dana R, Jurkunas UV: Differentiation potential of limbal fibroblasts and bone marrow mesenchymal stem cells to corneal epithelial cells. Stem Cells 2014, 32:717-729
30. Joyce NC, Zhu CC: Human corneal endothelial cell proliferation: potential for use in regenerative medicine. Cornea 2004, 23:S8-S19

31. Schmedt T, Chen Y, Nguyen TT, Li S, Bonanno JA, Jurkunas UV: Telomerase immortalization of human corneal endothelial cells yields functional hexagonal monolayers. PLoS One 2012, 7: e51427

32. Okumura N, Kusakabe A, Hirano H, Inoue R, Okazaki Y, Nakano S, Kinoshita S, Koizumi N: Density-gradient centrifugation enables the purification of cultured corneal endothelial cells for cell therapy by eliminating senescent cells. Sci Rep 2015, 5:15005

33. Zhao M, Isom SC, Lin H, Hao Y, Zhang Y, Zhao J, Whyte JJ, Dobbs KB, Prather RS: Tracing the stemness of porcine skin-derived progenitors (pSKP) back to specific marker gene expression. Cloning Stem Cells 2009, 11:111-122

34. Toma JG, Akhavan M, Fernandes KJ, Barnabe-Heider F, Sadikot A, Kaplan DR, Miller FD: Isolation of multipotent adult stem cells from the dermis of mammalian skin. Nat Cell Biol 2001, 3: $778-784$

35. El-Helou V, Beguin PC, Assimakopoulos J, Clement R, Gosselin H, Brugada R, Aumont A, Biernaskie J, Villeneuve L, Leung TK, Fernandes KJ, Calderone A: The rat heart contains a neural stem cell population; role in sympathetic sprouting and angiogenesis. J Mol Cell Cardiol 2008, 45:694-702

36. Palchesko RN, Lathrop KL, Funderburgh JL, Feinberg AW: In vitro expansion of corneal endothelial cells on biomimetic substrates. Sci Rep 2015, 5:7955

37. Peh GS, Chng Z, Ang HP, Cheng TY, Adnan K, Seah XY, George BL, Toh KP, Tan DT, Yam GH, Colman A, Mehta JS: Propagation of human corneal endothelial cells: a novel dual media approach. Cell Transplant 2015, 24:287-304

38. Snyder JC, Rochelle LK, Lyerly HK, Caron MG, Barak LS: Constitutive internalization of the leucine-rich $\mathrm{G}$ protein-coupled receptor-5 (LGR5) to the trans-Golgi network. J Biol Chem 2013, 288: 10286-10297

39. Tomita Y, Matsumura K, Wakamatsu Y, Matsuzaki Y, Shibuya I, Kawaguchi H, Ieda M, Kanakubo S, Shimazaki T, Ogawa S, Osumi N, Okano H, Fukuda K: Cardiac neural crest cells contribute to the dormant multipotent stem cell in the mammalian heart. J Cell Biol 2005, 170:1135-1146

40. Ma K, Fox L, Shi G, Shen J, Liu Q, Pappas JD, Cheng J, Qu T: Generation of neural stem cell-like cells from bone marrow-derived human mesenchymal stem cells. Neurol Res 2011, 33:1083-1093

41. Liu Y, Han SS, Wu Y, Tuohy TM, Xue H, Cai J, Back SA, Sherman LS, Fischer I, Rao MS: CD44 expression identifies astrocyte-restricted precursor cells. Dev Biol 2004, 276:31-46

42. Srinivas SP: Dynamic regulation of barrier integrity of the corneal endothelium. Optom Vis Sci 2010, 87:E239-E254

43. Okumura N, Koizumi N, Kay EP, Ueno M, Sakamoto Y, Nakamura S, Hamuro J, Kinoshita S: The ROCK inhibitor eye drop accelerates corneal endothelium wound healing. Invest Ophthalmol Vis Sci 2013, 54:2493-2502

44. Okumura N, Nakamura T, Kay EP, Nakahara M, Kinoshita S, Koizumi N: R-spondin1 regulates cell proliferation of corneal endothelial cells via the Wnt3a/beta-catenin pathway. Invest Ophthalmol Vis Sci 2014, 55:6861-6869

45. Arbelaez JG, Price MO, Price FW Jr: Long-term follow-up and complications of stripping descemet membrane without placement of graft in eyes with Fuchs endothelial dystrophy. Cornea 2014, 33: $1295-1299$

46. Balachandran C, Ham L, Verschoor CA, Ong TS, van der Wees J, Melles GR: Spontaneous corneal clearance despite graft detachment in descemet membrane endothelial keratoplasty. Am J Ophthalmol 2009, 148:227-234.e1

47. Baydoun L, Ham L, Borderie V, Dapena I, Hou J, Frank LE, Oellerich S, Melles GR: Endothelial survival after descemet membrane endothelial keratoplasty: effect of surgical indication and graft adherence status. JAMA Ophthalmol 2015, 133:1277-1285 
48. Joyce NC, Harris DL, Mello DM: Mechanisms of mitotic inhibition in corneal endothelium: contact inhibition and TGF-beta2. Invest Ophthalmol Vis Sci 2002, 43:2152-2159

49. Joyce NC, Zhu CC, Harris DL: Relationship among oxidative stress, DNA damage, and proliferative capacity in human corneal endothelium. Invest Ophthalmol Vis Sci 2009, 50:2116-2122

50. Krachmer JH, Purcell JJ Jr, Young CW, Bucher KD: Corneal endothelial dystrophy. A study of 64 families. Arch Ophthalmol 1978, 96:2036-2039

51. Jurkunas UV, Bitar MS, Funaki T, Azizi B: Evidence of oxidative stress in the pathogenesis of fuchs endothelial corneal dystrophy. Am J Pathol 2010, 177:2278-2289
52. Halilovic A, Schmedt T, Benischke AS, Hamill C, Chen Y, Santos JH, Jurkunas UV: Menadione-induced DNA damage leads to mitochondrial dysfunction and fragmentation during rosette formation in Fuchs endothelial corneal dystrophy. Antioxid Redox Signal 2016, 24:1072-1083

53. Johnson DH, Bourne WM, Campbell RJ: The ultrastructure of Descemet's membrane. I. Changes with age in normal corneas. Arch Ophthalmol 1982, 100:1942-1947

54. Chen KH, Harris DL, Joyce NC: TGF-beta2 in aqueous humor suppresses S-phase entry in cultured corneal endothelial cells. Invest Ophthalmol Vis Sci 1999, 40:2513-2519 